\title{
Experiment research on lowering sintering temperature of ceramic based on steel slag
}

\author{
Jingyu Zhang, Yanbing Zong ${ }^{*}$, Teng Ma
}

School of metallurgical and ecological engineering, University of science and technology, Beijing, No.30, Xueyuan road, Beijing, 100083, China

s20140285@xs.ustb.edu.cn

Keywords: low temperature, ceramic, steel slag, glass

Abstract. Waste derived ceramics were prepared successfully using a constant amount (50 wt.\%) of steel slag and a different amount of glass by conventional sintering process. The influence of glass content on sintering temperature was researched. The phase and microstructure of the final ceramics were observed by X-ray diffraction (XRD) and scanning electron microscopy (SEM). What's more, the developed ceramics were characterized by water absorption, linear shrinkage and flexural strength. The results show that the sintering temperature is relatively declined when the amount of glass is between $10 \mathrm{wt} . \%$ and $20 \mathrm{wt} . \%$.

\section{Introduction}

In steel production, substantial amount of steel slag is generated every year. In 2012, 9300 tons of steel slag is generated in China while only $22 \%$ of the steel slag is recycled. Recycling steel slag in large amount has become an urgent issue. Of all the reusing methods, incorporating steel slag into ceramic making is an alternative way, which has been studied by many researchers [1-3].

Similar to the steel industry, the ceramic industry also consumes great amount of energy. The sintering temperature of traditional ceramic is over $1200^{\circ} \mathrm{C}$. Lowering the sintering temperature is of great potentiality to save energy. There are several methods used to lower the sintering temperature: Reducing the particle size of raw materials to enhance the activation, adopting special sintering process (such as microwave sintering), and adding flux agent.

Low temperature sintering and making ceramic with industry wastes have become a trend. This work aims to lower the sintering temperature of ceramic based on steel slag by adding glass as flux agent. Glassy phase in ceramics will appear in lower temperature because of the low softening temperature of glass. This will accelerates the sintering process and lowers the sintering temperature of ceramic.

\section{Experiment}

The main materials in this work are glass and steel slag from a typical steel plant in Shandong province, China. Due to the poor plasticity of the above materials, some clay is added. The main content of raw materials is shown in table 1 .

\begin{tabular}{lcllllllll}
\multicolumn{1}{c}{ Table 1 Content of raw materials } & \multicolumn{3}{c}{ w/\% } \\
\hline & $\mathrm{CaO}$ & $\mathrm{Fe}_{2} \mathrm{O}_{3}$ & $\mathrm{SiO}_{2}$ & $\mathrm{MgO}$ & $\mathrm{Al}_{2} \mathrm{O}_{3}$ & $\mathrm{MnO}$ & $\mathrm{Na}_{2} \mathrm{O}$ & $\mathrm{K}_{2} \mathrm{O}$ & others \\
\hline glass & 10.28 & 0.62 & 71.38 & 3.46 & 0.94 & 0.04 & 12.52 & 0.41 & 0.35 \\
steel slag & 48.39 & 19.82 & 15.55 & 5.24 & 3.41 & 2.41 & 0.11 & 0.16 & 4.91 \\
clay & 0.14 & 2.37 & 51.37 & 0.25 & 42.62 & 0.02 & - & 1.98 & 1.25 \\
\hline
\end{tabular}


In the study, five ceramic compositions contained a constant amount of $50 \mathrm{wt} \%$ steel slag were researched. The amount of glass in the five batches is $0,5 \mathrm{wt} . \%, \quad 10 \mathrm{wt} . \%, 15 \mathrm{wt} . \%$ and 20 wt.\% (labeled SS-0, SS-5, SS-10, SS-15 and SS-20 respectively).

All the raw materials were milled below $180 \mu \mathrm{m}$ first and then mixed according to the compositions listed above. The initial mixtures with 7 wt. $\%$ water content were prepared, homogenized and granulated through 80 mesh $(180 \mu \mathrm{m})$ sieve. After that, dry powders were pressed in a rectangular die $(50.00 \times 7.10 \times 18.60 \mathrm{~mm})$ at a pressure of $25 \mathrm{MPa}$. Samples were then sintered in an electric muffle furnace in air atmosphere after dried at $105^{\circ} \mathrm{C}$ for 10 hours. The heating temperature is from 1090 to $1140^{\circ} \mathrm{C}$ with the heating rate of $10^{\circ} \mathrm{C} / \mathrm{min}$.

The samples' flexural strength was measured by three-point method, and the water absorption was carried out using the liquid displacement method according to Archimedes principle. The phases of the initial mixture and the samples sintered at different temperature were characterized by X-ray diffraction and the microstructure of the samples was obtained by scanning electron microscopy (SEM). Flexural strength, linear shrinkage and water absorption data reported in this paper are all averaged over 5 measurements.

\section{Results and discussions}

Water absorption and linear shrinkage. The densification behavior of the samples was confirmed by water absorption and linear shrinkage, which are illustrated in figure 1. As can be observed from the figure, the sintering process starts at $1120^{\circ} \mathrm{C}$ in SS-10, $1110^{\circ} \mathrm{C}$ in SS- 15 and $1100^{\circ} \mathrm{C}$ in SS-20, while the overfiring of these three samples is observed at $1130-1140^{\circ} \mathrm{C}$ in SS-10, $1120-1140^{\circ} \mathrm{C}$ in SS-15 and SS-20. At $1110^{\circ} \mathrm{C}$, the water absorption of SS-15 and SS-20 is $0.03 \%$ and $0.10 \%$, which are much lower than the items of Chinese National Standard (0.5\%). For SS-0 and SS-5 samples, on the contrary, cannot be accepted due to the excessive water absorption.
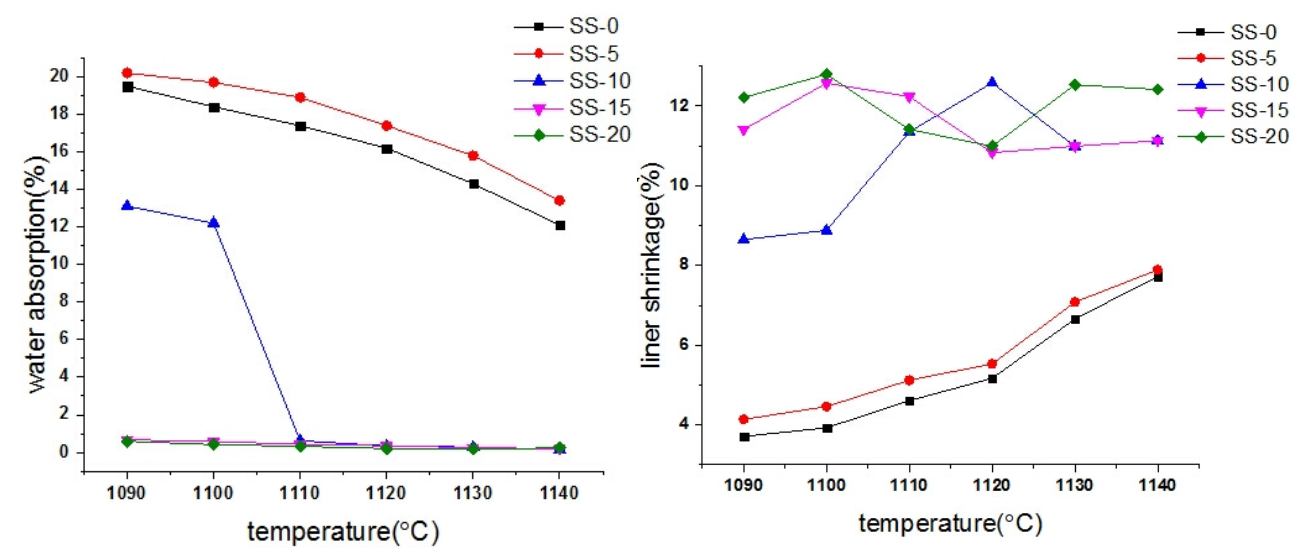

Fig 1 Variation of water absorption and liner shrinkage as a function of firing temperature

Flexural strength. Figure 2 shows the flexural strength of ceramics with the change of firing temperature. Flexural strength of SS-10, SS-15 and SS-20 is higher than the Chinese National Standard (35MPa) in the firing temperature. The highest value of the three samples is $106.8 \mathrm{MPa}$ of SS-10 at $1120^{\circ} \mathrm{C}, 103.1 \mathrm{MPa}$ of SS- 15 in $1110^{\circ} \mathrm{C}$ and $106.6 \mathrm{MPa}$ of SS-20 in $1100^{\circ} \mathrm{C}$, which is much greater than the Chinese National Standard. 


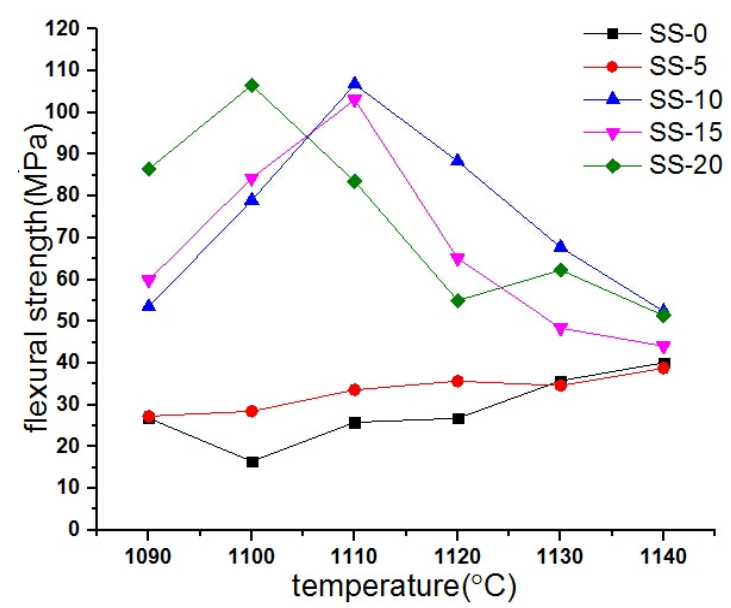

Fig 2 Variation of flexural strength in ceramic as a function of firing temperature

XRD and SEM analysis. The analysis above shows that only compositions SS-10, SS-15 and SS-20 are qualified. To further study the properties of the samples, XRD measurements and SEM tests were carried out. The XRD spectra of samples with different content of glass are illustrated in figure 3. As can be seen from the figure, the main phase of the samples is diopside, augite, and anorthite. It is noteworthy that the amount of anorthite increases with the amount of glass. According to Sarkar's research [4], due to the large difference in thermal expansion coefficient between the glassy phase and the anorthite grain during the cooling process, a strong pre-stress on the glassy phase that surrounds the anorthite grain will be produced, which will improve the flexural strength.

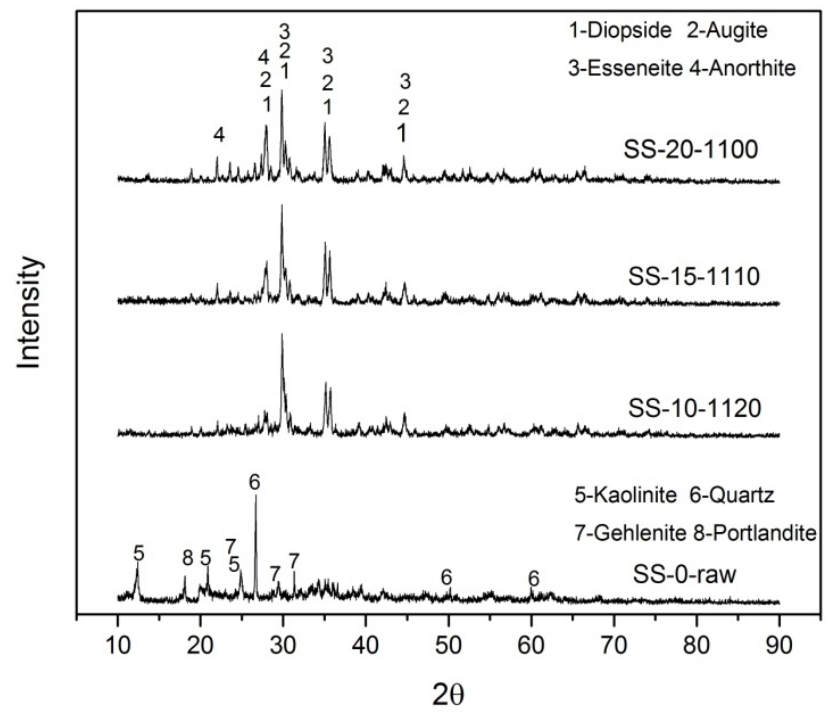

Fig 3 XRD spectra of different samples

The microstructure of ceramic with the highest flexural strength is shown in figure 4 . It can be observed that, from a to c, the grain size of samples is reduced. No obvious pores are found in the SEM images. According to Campos et al [5], glassy phase in the ceramic will bind up the pores, reduce chances of crack propagation and eventually improving properties of ceramics. This may explain the reason why the flexural strength of ceramics in this research is so high. 


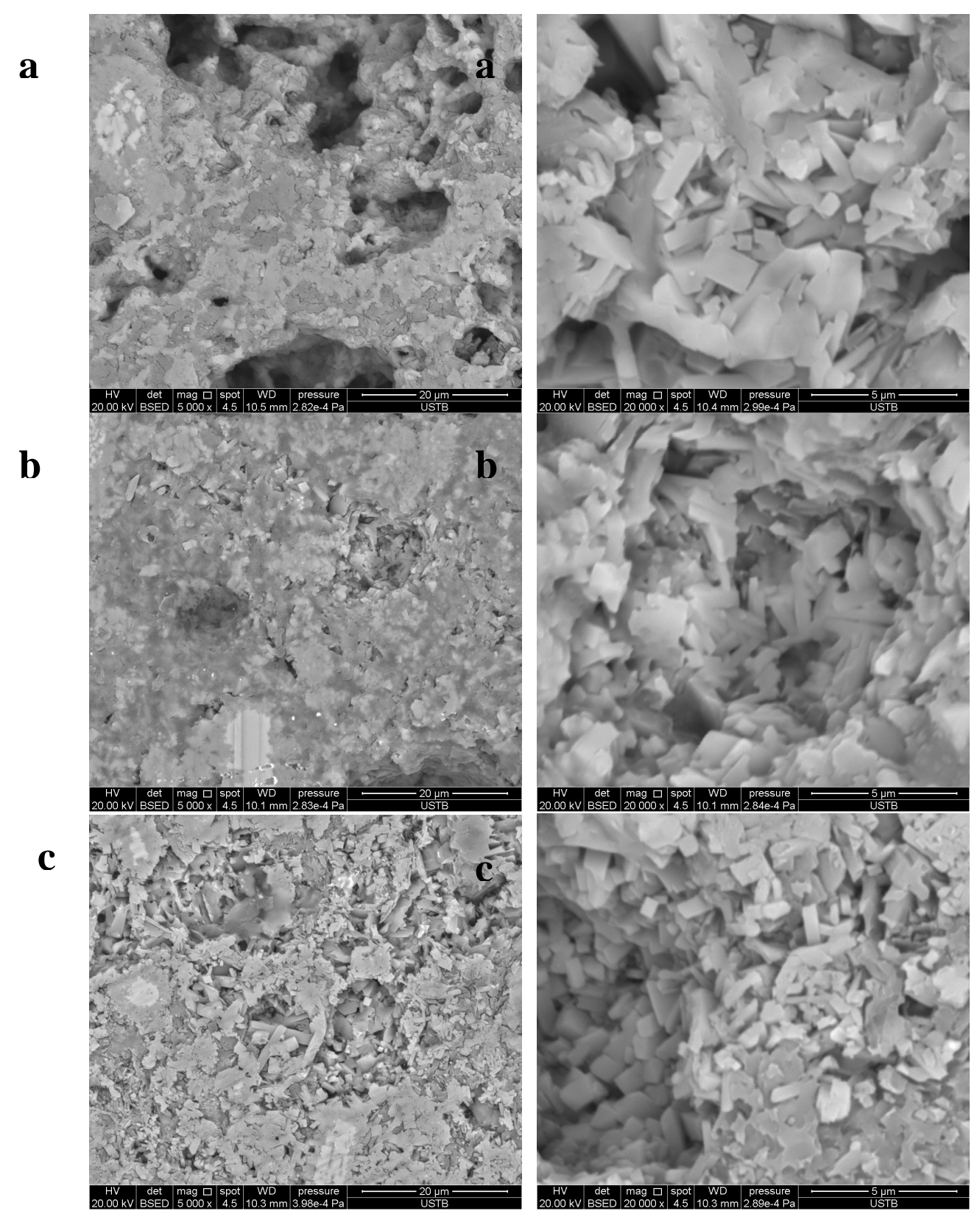

Fig 4 SEM images of different samples at lowest sintering temperature: (a)SS-10-1120, (b)SS-15-1110, (c)SS-20-1100

\section{Conclusions}

In this work, ceramics containing $50 \mathrm{wt} . \%$ of steel slag were prepared and the influence of glass content on sintering temperature is researched. Based on the analysis above, it can be concluded that:

(1)The lowest sintering temperature of the qualified ceramics based on steel slag is $1100^{\circ} \mathrm{C}$, which is much lower than the widely used sintering temperature in industry.

(2)The highest flexural strength of the ceramic is $106.8 \mathrm{MPa}$, which is three times of the National Standard.

(3)10 wt.\%-20 wt.\% addition of glass may lower ceramics' sintering temperature and improve their properties. 


\section{Acknowledgements}

The financial support of the National Natural Science Foundation of China (Grant No.51274042 and No.51474028) is gratefully acknowledged.

\section{References}

[1]Favoni C., Minichelli D., Tubaro F., et al. Ceramics International, 2005, (31): 697-702.

[2]Badiee H., Maghsoudipour A., Raissi Dehkordi B. Advances in applied ceramics, 2008, (107): 111-115.

[3]Bai H., Liu P., Ai X., Zhao L., Tang Q., Zheng S. Advances Materials Research,150-151(2009): 133-138.

[4]Siddiqui A.R, Pal M, Bhattacharya D. Global nest journal, 2014, (16): 587-596.

[5]Campos M., Velasco F., Martinez M.A., Torralba J.M. Journal of Europe ceramic society, 2004, (24): 811-819. 